\title{
Target position and practice in the identification of letters in varying contexts: A word superiority effect
}

\author{
THOMAS H. CARR \\ George Peabody College, Nashville, Tennessee 37203 \\ STEPHEN W. LEHMKUHLE, BRIAN KOTTAS, and EILEEN C. ASTOR-STETSON \\ Vanderbilt University, Nashville, Tennessee 37235 \\ and \\ DREW ARNOLD \\ George Peabody College, Nashville, Tennessee 37203
}

\begin{abstract}
A forced-choice detection paradigm controlling for postperceptual inference was used to investigate letter identification in three-position displays. Letters from a predesignated set of four targets appeared singly, in strings of noise characters, in unpronounceable nonsense strings, and in words. Subjects knew which context would occur, but did not know which of the three display positions would contain the target. Correct detection data were collected at constant exposure duration over five testing sessions. Overall identification accuracy was higher in words than in all other contexts, the first word superiority effect to be found with targets specified in advance since Reicher's (1969). This effect remained constant over sessions. An interaction between context type and target position showed enhanced accuracy for initial and terminal letters in words, but depressed accuracy at initial and terminal positions in other contexts. This was interpreted to mean that prior knowledge of context is used to alter the dynamics of perceptual analysis.
\end{abstract}

In 1969, Reicher reported a word superiority effect, in which letters were more accurately identified when presented in words than when presented alone or in nonsense strings. Since then, much research has been directed toward defining the experimental conditions under which a word superiority effect can be found, and inferring from those conditions the locus of the effect in the course of information processing (e.g., Bjork \& Estes, 1973; Estes, 1975; Johnston \& McClelland, 1973, 1974; Massaro, 1973; Thompson \& Massaro, 1973). The major theoretical question in these studies has been whether context changes the perceivability of target letters or affects postperceptual processes responsible for generating and choosing among possible responses (Estes, 1975; Massaro, 1973).

To date, studies have been nearly uniform in obtaining a word superiority effect only when a recognition paradigm is used, in which response alternatives are presented after exposure of the target-containing stimulus (see Estes, 1975, for review). Thompson and

The authors are grateful to Robert Fox for his guidance in conducting this research and to John Bransford for his comments during preparation of the manuscript. The research was supported in part by NIH Grant EY00590 and NICHD Grant 5P01HD00973. Address correspondence to Thomas H. Carr, now at the Department of Psychology, University of Oregon, Eugene, Oregon 97403.
Massaro (1973) reported that subjects in the recognition paradigm appear to make their decisions about target identity before viewing the postexposure response alternatives. This implies that subjects could use redundancy, or higher-order information inferred from regularities of letter sequencing, to increase identification accuracy by restricting potential responses when target letters are embedded in words.

As a test of this hypothesis, Thompson and Massaro (1973) had subjects memorize a fourletter target set. A forced-choice detection paradigm was then used to measure letter identifiability when letters were presented alone, in three-letter words, or in three-letter nonsense strings. The target letter always appeared in the center position of the threeposition displays. The three contexts were randomized, and subjects never knew which context would occur on any given trial. Subjects were practiced heavily before data collection began. Thompson and Massaro reasoned that knowledge of response alternatives would be incorporated into perceptual processing over practice, eliminating the effects of redundancy. Under these conditions, identification accuracy was highest for letters alone and did not differ for letters in words or in nonsense strings. The authors concluded that the word superiority effect was postperceptual and resulted from the use of 
redundancy to limit response possibilities. However, since data were not recorded during practice sessions, it was not possible to test the assumption that advantages due to redundancy, and hence the word superiority effect, had been slowly eliminated over trials.

Johnston and McClelland (1974) offered an alternative explanation of Thompson and Massaro's findings. Johnston and McClelland found a word superiority effect when subjects focused on the midpoint of a four-letter display and attempted to perceive the stimulus as a whole, with no information provided about target position. When subjects were informed about the position of the target letter and instructed to focus on that position, however, performance was better for letters in nonsense strings than for letters in words. Johnston and McClelland therefore proposed that Thompson and Massaro's failure to find a word superiority effect was due to subjects' adopting a position-focus strategy as a consequence of knowing that the target letter would always appear in the same position.

Procedural differences between the two studies make it difficult to evaluate the focusing-strategy argument. Johnston and McClelland employed a recognition paradigm with subjects practiced only enough to establish preexperiment thresholds. These are the conditions Thompson and Massaro avoided in order to eliminate the effects of redundancy. In addition, Johnston and McClelland used blocked rather than randomized context presentation. Their subjects knew in advance of all trials the context in which the target letter would be embedded. Thompson and Massaro's subjects did not. Thus, while Johnston and McClelland's results are striking, they were obtained under conditions quite different from those of Thompson and Massaro.

The present experiment attempts to clarify the two major issues raised in comparing Thompson and Massaro's (1973) study with Johnston and McClelland's (1974). The first is the effect of practice on letter identification in various contexts. The second is the effect of focusing on a particular target position vs. trying to take in the stimulus as a whole. A forcedchoice detection paradigm with predesignated targets was used to control for postperceptual inference. Stimuli were constructed so that distractor characters alone did not distinguish among the response alternatives. Stimulus presentation was blocked by context type, and subjects were informed which context would occur in each block. This was done to eliminate variability associated with subjects' guessing whether the stimulus seen on any given trial had systematic structure from which letter patterns might be inferred. Feedback was given after each trial to facilitate reduction of variability related to task familiarity and response selection.
The only information subjects did not have was the position in which the target letter would appear. Subjects were instructed to fixate the center of a preexposure mask, which corresponded to the middle position of the three-position stimulus displays. They were then required to identify target letters that could appear in any of the three display positions. If fixating a particular display position reduces the identifiability of letters appearing at that position in words but increases their identifiability in other contexts, as suggested by Johnston and McClelland, then an interaction would be expected between context and the position of the target letter. If Johnston and McClelland's finding does not hold with postperceptual controls in effect, then no interaction should occur. In addition, examining performance over sessions as a function of context type should test Thompson and Massaro's claim that word advantages diminish with practice when target alternatives are known in advance. With postperceptual processes controlled, any word superiority effect occurring in the absence of a Context by Sessions interaction would have to be assigned a perceptual locus. The present study, then, offers a strong test for influences of context on letter perception.

\section{METHOD}

\section{Subjects}

Ten adults from the academic community of George Peabody College and Vanderbilt University participated in the experiment. Each subject served in one session per day for 6 consecutive days and was paid $\$ 2 / \mathrm{h}$.

\section{Stimuli}

Four context types were employed. These were three-letter words, three-letter unpronounceable nonsense strings, letters presented alone, and letters presented with two noise characiers. The four-letter target set was $P, R, C$, and $G$, the targets used by Thompson and Massaro (1973). The subjects were given the target set verbally at the beginning of the experiment and asked to memorize it. Each target letter was then presented equally often in each of the three display positions for all context types. Distractor characters alone did not distinguish among the targets at any display position. The word stimuli were POT, ROT, COT, GOT; APE, ARE, ACE, AGE; TAP, TAR, TAC, and TAG. The nonsense strings were PKS, RKS, CKS, GKS; SPL, SRL, SCL, SGL; FQP, FQR, FQC, and FQG. The single-letter stimuli were of the forms P-blank-blank, blank-P-blank, and blankblank-P. The $\%$ sign was used as the noise character in the letterplus-noise stimuli, which took the forms $\mathrm{P} \% \%, \% \mathrm{P} \%$, and $\% \% \mathrm{P}$. In the typeface used, the $\%$ sign occupies an area approximately equal to the area occupied by uppercase letters and does not selectively mimic any letter (cf. Bjork \& Estes, 1973). Stimuli were typed in capitals on white index cards with an IBM Selectric II typewriter. Display positions were separated by one typewriter space. Position 2 was always centered in the display. Target letters subtended approximately $.3 \mathrm{deg}$ of visual angle vertically and .2 deg horizontally. Three-character displays subtended approximately $I$ deg of visual angle horizontally.

A rectangular, high-contrast patterned mask similar to Johnston and McClelland's (1973) was displayed at all times except during stimulus exposure. This mask subtended $1.5 \mathrm{deg}$ of visual angle vertically and $2.8 \mathrm{deg}$ horizontally. The center point of the 


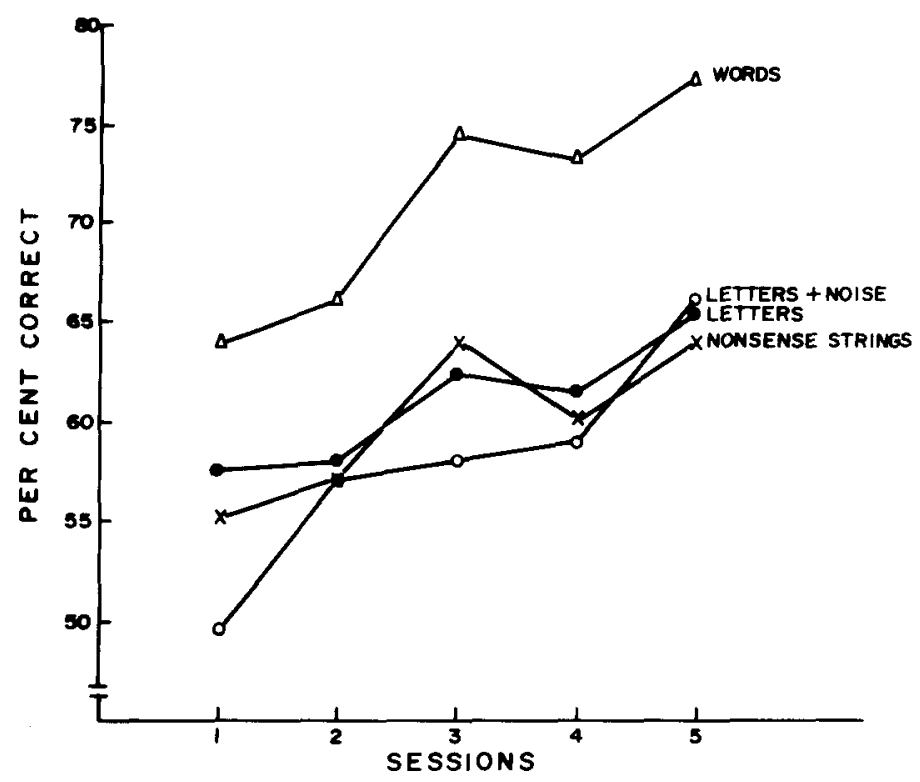

Figure 1. Percent correct as a function of context type and sessions. Each data point is averaged across 10 subjects with 48 observations per subject.

mask coincided with Position 2 of the stimulus display. Luminance of the stimulus and masking fields was $175 \mathrm{~cd} / \mathrm{m}^{2}$.

\section{Apparatus}

Stimuli were displayed in a Scientific Prototype two-channel tachistoscope. A chincup was used to standardize head position and viewing distance..

\section{Procedure}

The first session was used to establish a baseline exposure duration for each subject. Using a modified staircase method, a duration producing approximately $60 \%$ correct responses was obtained for each of the four context types. A single exposure duration for each subject was calculated by subtracting $15 \mathrm{msec}$ from the average of these four durations. Pilot work indicated that this procedure yielded an initial performance level that was above chance $(25 \%)$ but low enough to allow for improvement with practice. All stimuli in the five experimental sessions were run at this constant exposure duration. Mean baseline duration averaged across subjects was $82 \mathrm{msec}$.

Experimental trials were blocked according to context. A block consisted of two trials on each of the 12 stimuli in a context type. Stimulus occurrence was randomized within blocks. Two blocks of each context type were presented per session. Order of blocks was counterbalanced within and across sessions. Before each block, subjects were reminded of the four target letters and were told which context type would occur. They were instructed to focus on the center point of the mask at the beginning of each trial. After the experimenter indicated that a stimulus was in place, the subject presented the stimulus by pressing a hand-held microswitch. Subjects responded verbally. The experimenter recorded the response and told the subject whether the response was correct or incorrect.

\section{RESULTS}

The data for each subject were collapsed across context blocks within sessions. A 4 by 3 by 5 analysis of variance was performed on correct detection scores, with context type, target position, and sessions varied within subjects.

A main effect was found for context type, $F(3,27)=7.08, p<.01$. Newman-Keuls multiple comparisons showed that target letters were identified more accurately in words than in all other contexts $(p<.01)$. No other significant differences occurred among context types. A main effect was also found for sessions, $F(4,36)=8.93, p<.001$. The interaction between sessions and context type was not significant, $F<1.00$. This pattern of results suggests that the magnitude of the advantage for targets in words did not change with practice (see Figure 1).

In addition to these effects, a significant interaction occurred between context type and target position, $F(6,54)=3.17, p<.01$ (see Figure 2). Simple effects analyses of variance indicated that performance differed as a function of context type for Position $1(p<.01)$ and for Position $3(p<.01)$.

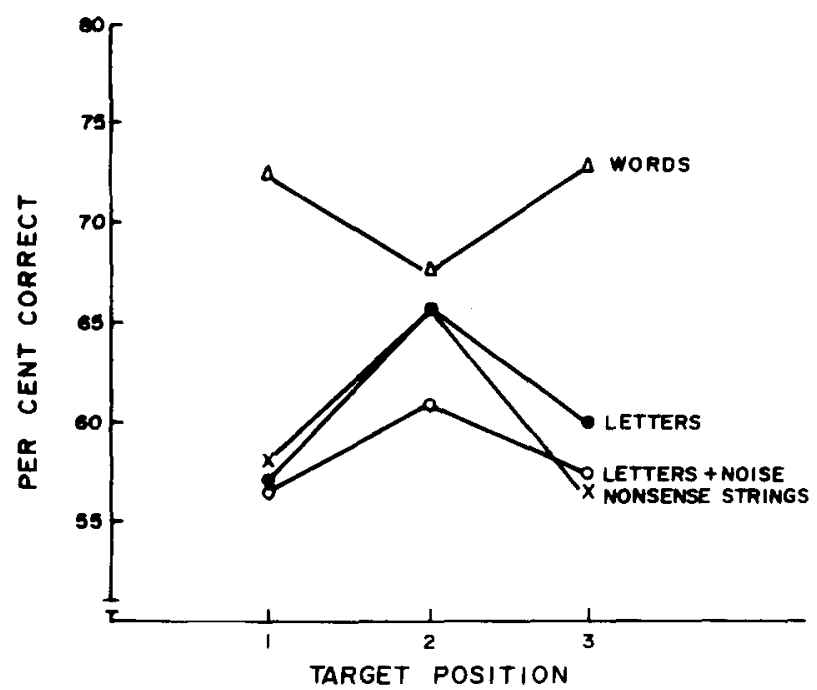

Figure 2. Percent correct as a function of context type and target position. Each data point is averaged across 10 subjects, with 80 observations per subject. 
The differences among context types at the center position were not significant. Newman-Keuls multiple comparisons showed that target letters were identified more accurately in words than in all other contexts at both the first and third target positions $(p<.01)$. No other significant differences among context types were found at these positions.

\section{DISCUSSION}

The results of this study show that targets were identified more accurately in words than in any of the other three context types, primarily because of performance differences at the end positions of the three-position stimuli. The effect appeared in the first session and remained constant throughout the experiment. Since the study was designed to place stringent control over postperceptual inferential processes, the results indicate an overall enhancement of perceivability for letters embedded in words.

This is the first investigation since Reicher's (1969) to find a word superiority effect with target alternatives provided in advance. It is also, however, the first study using a detection paradigm in which performance was measured at all display positions with stimuli blocked by context type. Subjects knew before stimulus exposure both the targets to be detected and the context type in which the target would appear. No word advantage other than Reicher's (1969) has ever been found in studies with randomized context occurrence, which prevents subjects from knowing the context type in advance of exposure. All other studies reporting word superiority have used stimuli blocked by context type, presumably allowing subjects to predict which context would occur on any particular trial. Given that expectancy can influence the functional unit of information extraction during perception (Aderman \& Smith, 1971), it appears that knowing the target will be part of a word may be prerequisite to the word superiority effect. Consistent with this hypothesis, the series of experiments by Estes (1975) demonstrates fairly convincingly that higher-order stimulus characteristics per se have little effect at the level of feature detection when subjects do not know whether to expect a word or a nonsense string, at least when exposure duration is short.

Prior knowledge of context type seems to be used by the perceiver to alter the dynamics of perceptual analysis, as indicated by the interaction between context type and target position. When targets were embedded in words, focusing on a target position interfered with letter identifiability at that position. For nonsense strings, letters plus noise, and letters alone, focusing on a target position facilitated letter identifiability at that position. Thus word contexts result in a different pattern of feature detection across the display than nonwords, increasing per- ceivability of display elements which are poorly identified in the three kinds of nonword stimuli examined. The result is an overall increase in the amount of information extracted from words relative to the other context types.

The nature of the Context by Position interaction impiies a reformulation of Johnston and McClelland's (1974) criticism of Thompson and Massaro's (1973) findings. Thompson and Massaro examined performance at only the center or focal position of their three-position displays. This is where we found target identifiability in words to be lowest and target identifiability in the other context types to be highest. Thus the word superiority effect may not have appeared in Thompson and Massaro's study even if their subjects had been told to take in the stimulus as a whole and had known which context type would occur. Indeed, Massaro (1973), again looking only at focalposition performance, failed to obtain a word superiority effect when comparing words, nonsense strings, and single letters blocked by context type.

The differences in perceptual dynamics identified in the present experiment are consistent with two rather independent lines of previous research on processing strings of characters. The performance across target positions for nonsense strings, letters plus noise, and letters alone might be predicted from studies of serial position effects in tachistoscopic report. Averbach and Coriell (1961) and Townsend (1973), among others, have found W-shaped performance functions for strings of unrelated characters, with a peak at the focal point of the display and depressed performance immediately to the left and right of the focal point. On the other hand, converging evidence predicting the performance across target position obtained for words in the present study is provided by research on word recognition. Bruner and O'Dowd (1958) found that identification latencies for visually presented words were increased most by transpositional spelling errors at the beginnings of words, an intermediate amount for errors at the ends of words, and least for errors at internal positions. Oleron (1970), using words constructed from an artificial alphabet, found a similar ordering by position for the effectiveness of letters with tails (analogous to $\mathrm{p}$ or $\mathrm{b}$, for example) as cues to word recognition. Several more studies have reported the importance of initial letters to successful word processing without finding evidence for consistent differential contributions from subsequent letter positions (e.g., Eriksen \& Eriksen, 1974; Goidsheider \& Muller as reported in Huey, 1908; Melville, 1957; Singer, Lappin, \& Moore, 1975). In general, then, it seems that initial letters are always critical to word processing, while terminal letters contribute more or less critical information depending on the nature of 
the task demands made upon the perceiver. In the present case, increased sensitivity to both initial and terminal letters may be a visual adaptation to the importance of these letters in defining the boundaries of vocalic subgroups during reading (Spoehr \& Smith, 1973).

\section{CONCLUSION}

The data reported here strongly suggest that the perception of individual letters which form a word differs from the perception of letters which occur alone or as part of an unsystematic string of characters, given that the perceiver knows in advance that he or she will be processing a word. The nature of the change in perception, which appears to involve a reallocation of attention across the elements of the stimulus being processed, may point toward organismic adaptations specific to literacy. Confirmation of these conclusions awaits further research, the first of which might attempt to replicate the present results while orthogonally varying advance knowledge of embedding context and response alternatives.

\section{REFERENCES}

Aderman, D.. \& S Sith, E. E. Expectancy as a determinant of functional units in perceptual recognition. Cognitive Psichology. 1971. 2. 117-129.

Averbach, E., \& Coriell, A. S. Short term memory in vision. Bill Sistem Technical Journal. 1961. 40. 309-328.

BJoRk. E.. \& Estes. W. K. Letter identification in relation to linguistic context and masking conditions. Memory \& Cognition, 1973, 1. 217.223.

Bruner. J. S., \& O'Dowd, D. A note on the informativeness of parts of words. Language and Speech, 1958, 1, 98-101.
Eriksen, B. A.. \& Eriksen, C. W. The importance of being tirst: A tachistoscopic study of the contribution of each letter to the recognition of four-letter words. Perception \& Psychophysics. 1974. 15. 66-72.

Estes. W. K. The locus of inferential and perceptual processes in letter identification. Joumal of Experimental Psychology: General, 1975, 104, 122-145.

HUEy, E. B. The psichology and pedagogy of reading. New York: Macmillan, 1908. (Reprinted. Cambridge, Mass: M.I.T. Press. 1968.)

Johnston. J. C.. \& MCClelland, J. L. Visual factors in word perception. Perception \& Psychophysics, 1973, 14. 365-370.

Johnston. J. C.. \& MCClelland, J. L. Perception of letters in words: Seek and ye shall not find. Science. 1974. 184. 1192-1193

Massaro. D. W. Perception of letters, words, and non-words. Journal of Experimental Psychology, 1973, 100. 349-353.

Melville, J. R. Word-length as a factor in differential recog. nition. American Journal of Psychology. 1957. 70. 316-318.

Oleron. P. Sur les stratégies dans J'identitication des mots. Journal de Psychologie Normal et Pathologique. 1970. 3. 313-323.

Reicher, G. M. Perceptual recognition as a function of meaningfulness of stimulus material. Joumal of Experimental Psychology. 1969. 81. 275-280.

Singer. M. H., Lappin. J. S.. \& Moore. L. P. The interference of various word parts on color naming in the Stroop test. Perception \& Psychophysics, 1975, 18, 191-193.

Spoenr. K. T.. \& Smith, E. E. The role of syllables in perceptual processing. Cognitive Psychology. 1973, 5. 71-89.

Thompson. M. C.. \& MASSARo, D. W. Visual information and redundancy in reading. Journal of Experimental Psychology. 1973. 98. 49-54.

TOWNSEND, V. M. Loss of spatial and identity information following a tachistoscopic exposure. Journal of Experimental Psychology. 1973, 98. 113-118.

(Received for publication November 24, 1975: revision accepted February 16, 1976.) 